\title{
LOCAL BODIES' EDUCATIONAL PROGRAMS AND ACTIONS TO RAISE ENVIRONMENTAL AWARENESS OF CLIMATE CHANGE IN THE PREFECTURE OF LARISSA IN GREECE
}

\author{
Bechlivani Sofia ${ }^{1}$, \\ Pavlis-Korres Maria ${ }^{2 i}$ \\ ${ }^{1}$ Geologist MSc, Med, \\ ${ }^{2}$ Associate Professor, SEDEd, \\ Aristotle University of Thessaloniki,
}

Greece

\section{Abstract:}

The present research aimed at documenting the educational actions and programs about climate change that have been implemented in the Prefecture of Larissa, Greece, and at investigating whether their design and implementation aligns with the principles of adult learning. It also sought to examine whether the participants of these programs have developed environmental awareness and whether they have adapted to the new conditions created by climate change. Following a qualitative methodological approach, this research conducted semi-structured interviews with local bodies' executives and educators who plan and organize educational programs and events within the scope of climate change. According to the findings of this study, the climate change-related programs implemented in the Prefecture of Larissa were mostly organized by public institutions, had a short duration, and did not always include a practical or experiential part. Their primary purpose was to lead to a more comprehensive approach towards environmental issues and to contribute to the citizens' and professionals' adaptation to the changes that have occurred due to climate change. Even though the analysis of target population needs and the program evaluation are generally considered as basic steps in the process of designing adult education programs, this study revealed that local institutions departed from following the abovementioned established practices. In the cases examined, the structure of the content and the implementation of the program were determined by the organizing bodies' knowledge and capacity. Furthermore, the educational events that offered experiential activities contributed to the participants' better understanding of the climate change phenomenon, motivated them to become more actively engaged with this issue and led them to the occasional undertaking of initiatives that signified their possible development of environmental awareness. The process of informing, raising awareness and helping people adapt to the consequences of climate change requires time, effort, and persistence by the local institutions and by the

i Correspondence: email sofiabehli@gmail.com, mariapavliskorres@nured.auth.gr 
state, who can achieve these goals by properly designing and implementing programs that meet the educational needs of the target population.

Keywords: adult education, climate change, local bodies, environmental awareness, environmental education, adult education program design

\section{Introduction}

Climate change constitutes one of the greatest contemporary problems, having serious environmental, social, and financial implications (European Commission, 2007). The primary cause of climate change is global warming, a phenomenon evoked by the concentrations of gaseous pollutants in the atmosphere. Such pollutants are carbon dioxide (CO2), methane ( $\mathrm{CH} 4)$ and nitrogen dioxide (N2O), which are mostly produced by anthropogenic activities. According to the Intergovernmental Panel on Climate Change (IPCC), the consequences of climate change in the $21^{\text {st }}$ century will be more intense and extreme weather events will appear with higher frequency. These conditions will bring changes in rural areas and natural habitats that will affect people's everyday lives (IPCC, 2014).

In order to address and adapt to climate change, society must be informed about this issue. When adequately informed, society will be able to actively participate in effective action plans for the mitigation of this phenomenon (European Commission, 2008). Education, training and wide participation in events and programs about climate change will ensure that people will gain adequate knowledge to adopt eco-friendly attitudes and become environmentally conscious (McKeown \& Hopkins, 2010). Climate change education becomes especially significant to areas that are vulnerable to such changes, as is the Region of Thessaly in Greece, where the particular research was conducted. Thessaly is a rural area whose economy and prosperity depend on agriculture, a field that is under immediate threat due to the effects of climate change (Kartalis et al., 2017).

The purpose of this research was to record the adult education actions and programs about climate change that are implemented in the Prefecture of Larissa, Greece, and to examine whether they have been designed and implemented having followed the principles and standards of adult education program design. It also intended to investigate whether the participants have developed environmental awareness and have adapted to the changes brought by climate change.

In the first part of this article, a literature review about climate change and the design of adult education programs is conducted. In the second part of this article, the main research data are presented and the findings are discussed. 


\section{Literature Review}

According to some definitions, climate change is a term used to describe the shifting weather patterns that occur at a global scale. More specifically, it refers to the climatic changes observed on the planet for a considerable amount of time (European Commission, 2007). With respect to environmental education, Jarvis (2004) defines it as the "education directed towards making people more aware of the need to protect the environment" (p. 68), while an educational program is a well-organized interventional action of an organization, which has clearly defined goals and includes a set of factors, processes and activities of a particular educational content (Rogers, 2007). Through participation in educational programs about climate change, people are expected to develop the environmental awareness necessary to understand the permissibility of certain actions with environmental implications (Jarvis, 2004).

Changes in climate may be due to natural causes or external reasons, such as human interventions in land use and atmospheric composition. Human's prolonged use of carbon, compared to the utilization other energy sources, causes high CO2 concentrations, which increase the greenhouse effect and favour climate change (IPCC, 2007). The latest figures indicate that the consumption of fossil fuels for human activities is the main factor causing greenhouse gas emissions (Mitigation, 2011). These emissions, combined with the loss of biodiversity, the use of traditional energy forms, the large-scale inflow of waste, the strong economic activity, and the overconsumption of energy etc., are responsible for climate change.

Extreme weather conditions such as floods, droughts, and high temperatures the effects of climate change - are phenomena which are nowadays encountered with higher frequency. As the earth's resources are shrinking, insecurity, poverty, increased refugee flows and hunger may be added to the long-term effects of climate change. However, global warming is not the only issue that will trouble humanity in the future years. Many animal species will be faced with extinction (European Commission, 2009), while climate change will have serious consequences in human health, natural ecosystems, and water resources. With respect to the economic sector, the factors most vulnerable to climate change are agriculture, forestry, and tourism, which are expected to face the gravest impact of this phenomenon (European Environmental Agency, 2016).

In order to prevent the negative effects of climate change, it is imperative that immediate action is taken towards the mitigation of this phenomenon and that the environmental laws and measures to avert climate change are rightly implemented (European Commission, 2007). Were the relevant legislation to be applied, Europeans Union's targets for the progressive reduction of greenhouse gas emissions could be met by 2050 (European Commission, 2007). Admittedly, the establishment of effective and integrated policies at a regional, national, and international level would contribute to the understanding of good practices, to the involvement of public and private institutions and to the implementation of adaptation measures across the range of the environmental policies. It is important for the citizens to actively participate in environmental protection 
through informed action plans which will ensure that the policies are indeed effective. Thus, the need to inform policymakers at local and regional level is presented, in order to gain insights on the consequences of climate change and to apply best practices for society's adaptation to this phenomenon (European Commission, 2008). As highlighted by Agenda 21, the achievement of convergent views and of broader consensus between different groups are prerequisites for the effective response to the degradation of the environment, with the local authorities initiating the dialogue between citizens, businesses, and institutions (Cotter \& Hannan, 1999). The map for Europe's and Greece's adaptation to climate change indicates that the implementation of national action plans is imperative not only in the process of adapting, but also in the process of mitigating this phenomenon (Adger et al., 2007). Local authorities and businesses hold an important role in the development of information campaigns and the enforcement of priorities that offer substantial solutions to the problems related to climate change (Laissy, 2008).

According to UNESCO (2005), Environmental Education supports the information and the adoption of a positive attitude and stance towards important environmental issues. Through actions to protect the environment and its biodiversity, environmental education highlights the concept of respect and the right that the next generations have to inherit a sustainable future. In addition to contributing to the public's information and development of environmental awareness, environmental education constitutes a valuable tool for the transmission of knowledge and expertise, as well as for the introduction of lifestyle changes that aim towards a more sustainable future. By being environmentally educated, people will be led to a better exploitation of the natural resources and to prosperity through democracy, world peace and security (Hopkins, Damlamian, \& Ospina, 1996). In the context of United Nations' actions for climate change, a contract was signed by the nations, similar to the Kyoto Protocol. Through its articles 6 and 10, the aforementioned protocol invites the governments to develop and apply educational programs to inform people on the impact of climate change (UNFCCC, 2012). Humans must analyze and explain the reasons behind their activities which worsen the issue of climate change, while also using the knowledge gained by environmental education in order to make their actions more sustainable. Therefore, the development of environmental awareness contributes with the knowledge, skills and attitude changes that are necessary for the application of strategies to mitigate climate change. When all the aforementioned goals are realized, societies will alter their consumption and production models and will become more resilient when dealing with change (Anderson, 2010).

According to UNESCO (2003) environmental education can be seen within the framework of adult education programs. While the content of adult education programs is multi-faceted, they follow specific principles and methods, in order to reach their ultimate goal. It is important that their design and implementation aligns with the principles of adult learning, which means that the planning of the programs should take into consideration the needs and lived experiences of the participants, in order to encourage them to think critically, to pursue justice and to welcome change at a personal 
or a social level (Leftheriotou \& Pavlis Korres, 2014). When participating in adult education programs, the trainees are given the opportunity to negotiate and adapt the main subject of the courses to their interests, a process which motivates them to conduct their own personal research (Knowles, Holton \& Swanson, 1998). With reference to the people eligible for the organization of adult education programs, the existing institutional framework (law 3879/2010, art. 7) dictates that such trainings can be implemented by Greek Municipalities, Regions and private institutions that are able to educate the interested individuals with respect to the National Lifelong Learning Program. The educational events that the aforementioned bodies carry out are mainly general-interest programs or awareness-building initiatives and actions catering for the implementation of the public policy and for the promotion of the communities' priorities (UNESCO, 2003).

According to the relevant literature, there are particular criteria that determine the effectiveness of an adult education program. Firstly, the program must be designed after having examined the program's design environment and the needs of the target population. During the planning phase, the organizers must also define the structure of its sections and specify the procedures that will be followed for its evaluation, organization, and implementation. More specifically, the examination of the programs' design environment is a twofold process, as it is constituted by research on the institution's internal and external environment. When analyzing the internal environment, the interested parties delve into the organizations' structure and operation and become familiar with the infrastructure and resources available to the institution, as well as with the philosophy it embraces. Moreover, when investigating the institution's variable external environment, the organizers analyze the different factors affecting its operation and specify the profile of the target population (Leftheriotou, 2014). Before initiating the implementation of the program, one must carry out research on the educational needs of the target population, for which their particular characteristics and motivation for participation must be taken into consideration. Therefore, it becomes evident that the educational programs must be designed by individuals who are able to identify and cater for the needs of the adult population (Boone, Safrit \& Jones, 2002). These individuals should also be able to structure the events' operation effectively and be familiar with the educational programs' evaluation procedures, in order to use the feedback provided to design more successful educational programs in the future (Boone, Safrit \& Jones, 2002). The analysis of the target population's educational needs guarantees that the organizers will determine the objectives of the program based on the needs identified, while, at the same time, ensuring its high quality and successful implementation (Knowles, 1980; Caffarella 1988, 2002; Moseley \& Heaney, 1994). After the needs analysis has been conducted, the organizers follow the official guidelines that have been established based on qualitative and quantitative criteria and select the kind of program that they will implement. These criteria mostly refer to the collection of adequate educational materials and teaching aids in order to support the participants' experiential learning and understanding of the content. (Jarvis, 1985; Elias \& Merriam, 
2005). The programs' design and evaluation are complementary procedures, since to evaluate a program means, in essence, to assess the success of the choices that were made when the program was designed and implemented (Boone, Safrit \& Jones, 2002).

The programs about climate change aim at helping individuals acquire knowledge, practice new skills, and develop environmental consciousness. The participants in these programs cultivate a sense of responsibility in relation to environmental issues and are encouraged to take action, to participate in the decisionmaking and influence the community towards embracing a new way of life (Mochizuki \& Bryan, 2015). This study will now report some studies on climate change and education, which have been conducted in the broader Region of Greece. In 2012, Brekovic carried out his postgraduate research in the University of Aegean, on the topic of climate change and the role of local authorities. This study highlighted the importance of fostering the collaboration between scientific bodies and local authorities, as their collective action would lead to a comprehensive understanding of climate change and to innovative and effective practices which facilitate people's adaptation to the new climatic conditions. In the years following, Badounas (2018) conducted another postgraduate research in the University of Aegean, a thesis which explored the views embraced by primary school teachers in the Prefecture of Dodecanese, on the topic of climate change and global warming. It was revealed that due to climate change being a very complex phenomenon, this issue requires more attention by the state in order for teachers to become qualitatively educated in this area. Their meaningful education in combination with the help provided by the Environmental Education Centers (EEC) and the competent ministries could result in successful educational programs that would be significantly beneficial to the students. Another relevant paper written recently is Pistela's (2020) postgraduate thesis in the Hellenic Open University (HOU), which investigated the climate change-related views, beliefs and attitudes embraced by Natural Sciences educators in active employment. This research underlined the need to incorporate climate change education in schools and to develop new programs and appropriate techniques for the environmental education of teachers. These conditions will ensure that the future generations will cultivate environmental awareness and will take action to protect the environment. Therefore, it becomes evident that local authorities and bodies such as the Environmental Education Centers play an institutional role in the planning and application of measures towards the mitigation of climate change and the adaptation to this phenomenon. The process of raising awareness and helping people adapt to the consequences of climate change requires time, effort, and persistence by the local institutions and by the state, who can achieve these goals by properly designing and implementing programs that meet the educational needs of the target population. 


\section{Materials and Methods}

The present research focuses on the design and the planning of environmental programs and actions about climate change that were organized by local authorities in the Prefecture of Larissa. Since the needs of the participants and the existing sociocultural and environmental context are parameters that need to be considered in order for an educational program to be successful, this study aimed examining the extent to which these factors were taken into account when the programs were designed. The main research aims were to highlight the actions that have already been carried out, to investigate the planning and implementation of educational programs organized by local authorities and to test whether the participants have developed a sense of individual and collective environmental consciousness.

The following research questions underpinned the present research:

1) What programs about climate change are implemented in the Prefecture of Larissa?

2) Do the climate change-related programs organized by local authorities follow the principles of adult learning and the specifications for effective design?

3) Are these programs conducive to the citizens' development of environmental consciousness and to their adaptation to the new conditions brought by climate change?

Based on the aforementioned research questions and the theoretical framework of the study, it was decided that a qualitative research approach would be followed, through semi-structured interviews with the organizations' executives and educators. These interviews explored their views on the process of planning and implementing adult education programs about climate change in the Prefecture of Larissa, and on the programs' contribution to the development of environmental consciousness.

The selection of the sample population was deliberate, mainly based on: a) the position they occupy in the operation of the local institution, since the research aimed at the interviewing the people responsible for the organization and implementation of programs about climate change and, in some cases, the trainers of these programs, b) their level of involvement in the Prefecture of Larissa and c) the representation of public and private institutions. The sample of the research was constituted by 10 interviewees, 8 of whom were responsible for the organization of the programs, while the remaining 2 were involved in them either as educators or as speakers. Of the 10 institutions participating in the study, 7 belonged to the public and 3 in the private sector. For the purposes of this research, a semi- structured questionnaire was created, comprised by 20 questions. The interviews were conducted mostly face-to-face -except for the three cases where they were carried out via Skype- and lasted for approximately 40 minutes.

After the interviews were recorded and transcribed, they were thematically analyzed (Polit \& Hungler, 1999; Guest, MacQueen \& Namey, 2011; Bernard, Wutich, \& Ryan, 2016). The results of the above mentioned analysis are presented and discussed below. 


\section{Results and Discussion}

The study showed that the majority of educational programs, actions and information campaigns related to climate change were developed by public institutions. More specifically, the events realized were mainly European actions or information programs on the issue of climate change, the training of professionals and the planning of strategic solutions to combat climate change etc. (Figure 1).

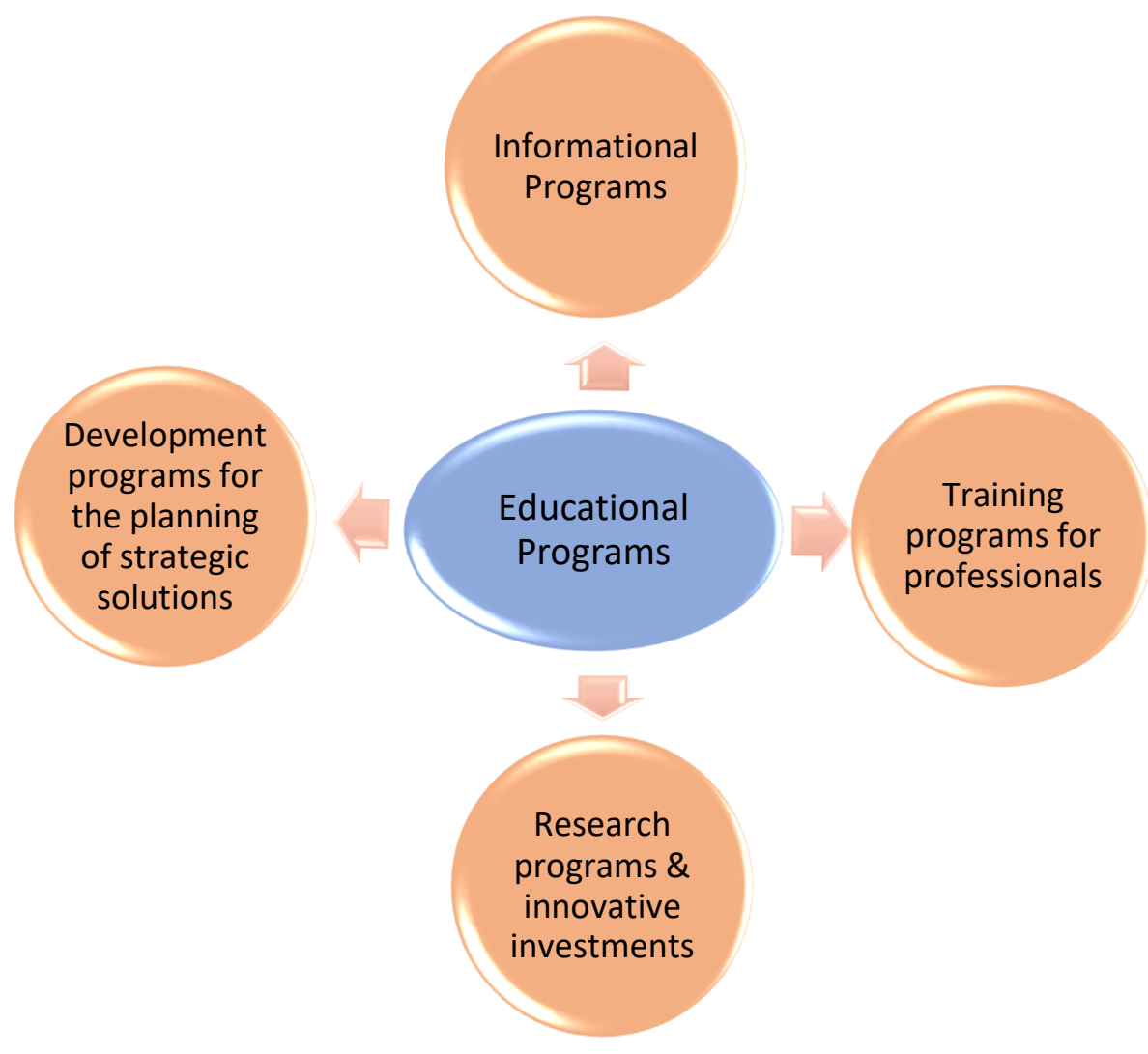

Figure 1: The educational programs implemented

The programs and actions that were implemented focused mainly on the intention to change the citizens' attitudes with respect to waste recovery, emerging techniques, recycling, water utilization, information on the progress of the national strategy for climate change etc. However, these actions and programs had a short duration - usually lasting for one day - and therefore failed in creating the necessary conditions for indepth information, discussion, and reflection on the issue of climate change. Half of the institutions which participated in this study mentioned that they organize programs within the scope of climate change on an annual basis. They further explained that they plan 1 to 4 events per year, prompted by European Union's Green Weeks, by scientific conferences and by the actions taken to protect water, to promote recycling and generally to combat climate change. As specifically mentioned by one participant: "These events mostly happen annually but they can happen at $\alpha$ more frequent rate... 'let's do it Greece' is an 
annual event, while another event in the context of a different program may be organized in the month following..." (P8), "There are many programs. There is a shift in interest towards climate change, as it is an issue that has many implications" (P10). Some of the programs and events implemented were not of a recurrent nature but were organized sporadically, depending on the local needs and the conditions existing in the community at that particular period. This was explained by P1: "There was an event organized in 2014 and the next one was organized 2017...They are planned depending on the needs, the specific conditions and on whether the public is willing to pay in order to attend such an event.".

Most local bodies stated that the climate change-related programs they organized were based on their voluntary initiative and were concerned with meeting the needs of the local community and economy. However, there were a few programs that were implemented as part of broader European programs - such as the European Green Weeks - and which extended over a longer period of time. Due to limited funding, the local bodies had to conduct these programs with minimal cost, at the expense of the programs' quality. P6 specifically mentioned that: “...they are funded by national resources and by the National Strategic Reference Framework (NSRF) and in view of the financial difficulties experienced lately, the funding has been minimized to a great extent...therefore, we are unable to host several-day seminars... The programs are totally free of charge for the participants". The scope of these programs about climate change was to develop a more comprehensive approach to environmental issues and to facilitate the people's adaptation to the climate change phenomenon. Therefore, the environmental goals that emerge are: to raise public awareness of environmental legislation, to sensitize the local communities on environmental protection and to assume responsibility with respect to environmental issues (Figure 2).

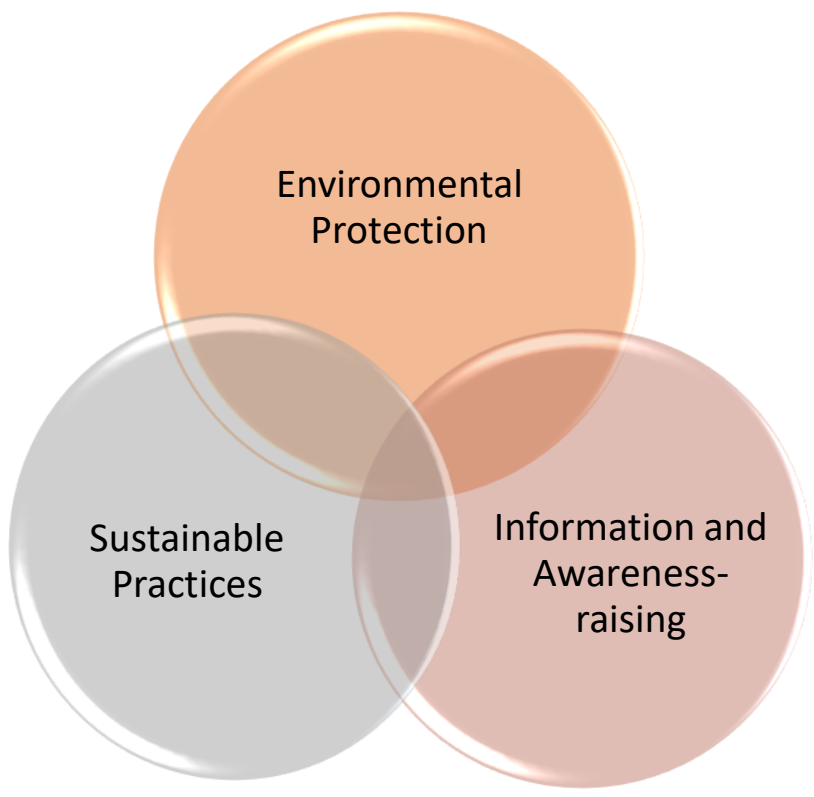

Figure 2: The scope of the educational programs on climate change

In order to design and carry out these programs, most institutions mentioned that they followed national and European policies, as well as the applicable legal framework. 
Despite the fact that the interviewees did not sufficiently elaborate on the aforementioned statements, some participants stated the following: "We applied international practices in order to create the conferences' agenda... we aspire to bring these practices in Greece through environmental education." (P1) and "It is necessary that the local authorities take into consideration the European policies and the existing legal framework when planning a one-day event or a seminar..., as these events have to be harmonized with the established policies and laws" (P4). However, some participants expressed the view that it is impossible to follow European trends and policies when designing environmental programs. The responsible parties do not have the necessary experience or time required to delve into such issues "...okay, I don't think we are getting there, since we have a lot of work to do... the ones who are making an effort towards this direction are very few. Personally, I am not adequately informed, and I don't have any free time to devote into gaining the necessary knowledge" (P7).

The interviewed institutions stated that the programs they organize are addressed to professionals of the technical or agricultural sector and to the general public. However, in most cases, the organizing institutions were not willing to consider the participants' needs during the programs' planning stage. More specifically, the institutions did not adhere to the principles of adult education in order to carry out a well-organized study of the participants' wants but designed the program according to their experience and knowledge of the problems and needs that exist in the community diachronically (Figure $3)$. In essence, this means that the organizers did not apply a clear and systematic method in order to collect information on the participants' needs, something that is illustrated by the following interview extracts: "We didn't plan an organized action to gain insights on the participants' needs, but we designed the program after detecting a scientific gap. It's not very wellorganized. We took this initiative with the aim of supporting the direction of the local economy and of the economy in general - towards a specific goal..." (P1), "The people working on these issues, especially the local authorities, are much more familiar with these problems than we are...we did not ask the public about the things they wanted to hear. The local authorities are the ones who knew about the existing problems and set the goals of the designed programs" (P5).

\section{Needs analysis}

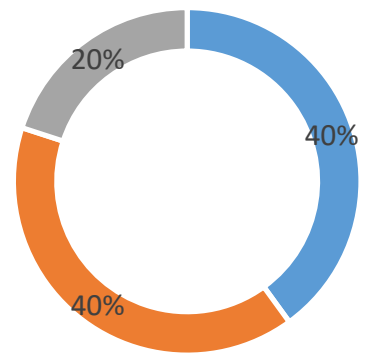

- Through an organized action - Experientially $\quad$ Not at all

Figure 3: Target population needs analysis in the process of designing educational programs 
Furthermore, the study revealed that the content of the program was designed and structured according to the capacity and knowledge available to the institution, as well as the specialties and interests of its speakers. In light of the experience the programs' speakers acquired through their participation in similar events, it is possible that they will share their views on the type of issues that will be included in the educational program and on the extent to which these topics will be discussed. In relation to this, some interviewees reported the following: "We tend to organize events internally, except for when we are organizing conferences. The planning of conferences demands an organizing and a scientific committee" (P4), "The speakers of the seminars are usually the ones who determine their specific structure. However, if...the program is about an issue that concerns us or a topic that requires our scientific knowledge, we can, of course, become involved in the planning process" (P7).

With reference to the infrastructure available to the institutions, the study revealed that they are able to acknowledge their deficiencies and needs, which are regarded as typical consequences of their reduced funding. However, in the cases where the institutions are financed by European Funds, the logistical needs are covered to a substantial extent. According to some participants' comments: "This has to do solely with the funding that we will receive for the implementation of a seminar. If we don't receive any funding, we will organize the seminar employing the materials and equipment that we own" (P6), "When it comes to European programs, their design is planned in advance, as it is something that has to be included in the proposal. Therefore, the organization of such programs has become a standardized process... However, when the organization of a program relies on our own resources, it is often difficult to find sufficient funds. In this case, one has to really focus on designing the program effectively..." (P8).

With respect to the speakers and trainers who contributed with their knowledge in the implementation of the programs, the study disclosed that they were chosen for these roles based on criteria that ensure the deep understanding of the issues in question. In essence, they were evaluated according to whether their area of expertise, as well as their studies and previous experience were related to the content of the program. In some cases, the trainer's communicative ability and pleasant personality were aspects that were conducive to their selection. However, the speaker-trainers' knowledge and previous work on adult education programs were not considered as necessary qualifications. The following views expressed by some interviewees are very indicative of the aforementioned statements: "We usually visit the trainer's social media profiles and watch their YouTube videos, in order to get a sense of the soft skills they possess, as well as their communicative ability and charisma... that is to say that I do not select trainers based on whether they have obtained a certification in adult education" (P4), "To tell you the truth, we did not put much thought into adult education..." (P5), "The trainers are selected by the different groups of the organizing associations. Therefore, there is always a person inside the association that will be responsible for a specific event. For example, if an environmental program is organized, the agriculturists will undertake its planning and design. To put is simply, it is possible to find someone of a relevant discipline." (P8). The majority of the realized events on climate change 
(6/10) had a predetermined agenda of presentations that could not be subject to any interventions or changes, during the time of their implementation. Some of the programs also included an experiential part such as bike rides, electro-mobility, reforestation etc., which engaged trainees in more active participation. Most institutions (7/10) are positive that the participants involved in these programs will develop environmental consciousness and will collectively take environmental actions, while they also abolish some everyday habits that worsen the issue of climate change.

Some local bodies $(4 / 10)$ are of the opinion that while the participants have not developed environmental awareness to a great extent, they can adopt different attitudes by being exposed to the various views shared in these programs. More specifically, the citizens that are immediately threatened by climate change - e.g., the farmers - are more accepting of the idea to change their behavior, since the unpredictable climatic conditions constitute a source of great concern for them. Moreover, few institutions (4/10) observed that some of the programs' participants took particular initiatives towards environmental protection such as: the organization of similar climate change-related programs, the cleaning of paths and coasts, changes in crops towards more eco-friendly options, energy saving, bicycle use etc. However, participants in short-term programs are unable to comprehend the gravity of the problem or take a critical stand towards it "Attitude changes are a very big issue... People do not realize that climate change has implications on their everyday life. Under these circumstances, I cannot say that the results are very satisfactory..." (P3), "I believe that many people opted for cars that run on gas without thinking of the environmental benefits of this change. This choice was underpinned by other reasons...It's also possible that extremely high price of electricity contributes to energy saving" (P8).

The content of the programs about climate change can initiate changes in the participants' attitudes, as it is an issue that poses great interest to the citizens and the professionals who strive to be resilient in these novel conditions and to raise the quality of their changing reality. However, it is undeniable that programs need to be updated according to the current research findings and to extend their short duration in order to help the participants acquire a comprehensive understanding of climate change and successfully adapt to the changes brought by this phenomenon. One participant stated: "...Therefore, in order for citizens to adapt to climate change, it is important to implement integrated programs that promote research and investment on these issues." (P1), "Citizens understand the different factors that affect climate change but are unfamiliar with its implications... even the cities that have made substantial progress on this part admit that while the local authorities, the experts and the people interested in these issues may have extensive knowledge of this topic, it cannot be guaranteed that the citizens have understood it thoroughly." (P3). Raising public awareness and changing citizens' attitudes on climate change are goals that could be fulfilled by fostering collaboration between institutions, by applying the knowledge gained, as well as by organizing programs that adhere to the principles of adult education (Figure 4). 


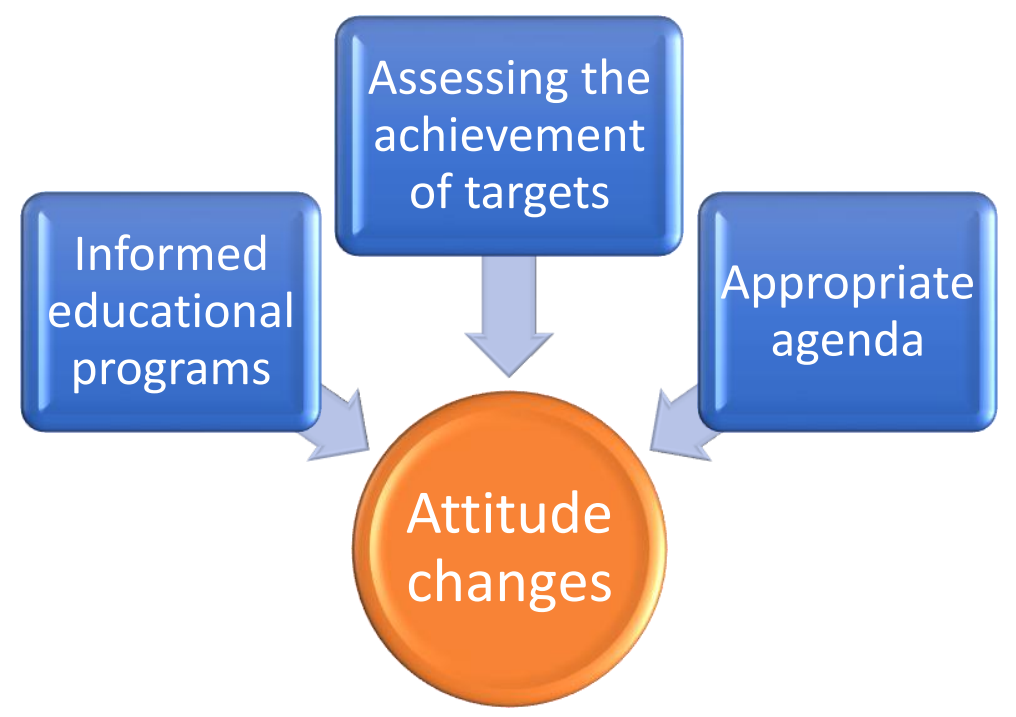

Figure 4: Attitude changes through participation in educational programs about the environment

The findings of the study indicated that public institutions prevailed in the organization of volunteering activities and information campaigns about climate change, in comparison with private institutions, which contributed mostly to the implementation of vocational trainings and innovation programs. This can be attributed to the fact that governments and public institutions have the responsibility to develop programs according to the National Lifelong Learning Program and to organize events which educate the citizens on environmental issues and facilitate their access to information (UNFCCC, 2012). However, private institutions must become more actively involved in order to contribute significantly to the citizens' meaningful information on climate change. Admittedly, the promotion of qualitative information, in combination with the improvement of environmental protection plans and of green practices are actions that can result to attitude changes (Laissy, 2008), can raise public awareness (European Commission, 2005) and ultimately facilitate the citizens' adaptation to climate change (UNFCCC, 2016).

One of the biggest problems encountered when implementing environmental programs is the dire economic situation of the local authority funds, which usually receive insufficient financing. While the aforementioned issues constitute serious obstacles in the process of planning environmental programs, some institutions do not quit this effort and opt to organize programs with minimal cost, at the expense of the quality and the duration of the program. This argument can be reinforced by Gouli's (2017) research findings, which indicated that the financial crisis and the insufficient funding had a negative impact on the application of innovative educational programs by institutions such as the Environmental Education Centers. Therefore, in order to successfully implement educational programs, it is important to detect the problems that the institutions face at an early stage, and to devise an effective plan to overcome them (Caffarella, 2002). 
When it comes to evaluating the achievement of the program's goals, the majority of institutions (6/10) did not provide a clear answer with regards to whether and how an assessment was carried out. They stated that they did not follow a particular procedure, as they did not possess the necessary experience and knowledge to do this productively: "It is extremely difficult as there is always the issue of communicating with the participants efficiently, something that has presently become more prominent than ever (P3), "I believe that the wide participation is an indication of the programs' success... Sometimes, you can understand whether it was successful just by looking at the level of participation in the specific event. In some cases, the participation may be wider than expected and the trainees may seem pleased with the program, suggesting that the event be repeated in the future. Obviously, this is something very positive" (P8), "We are not very experienced, as it is the first time that we are planning something along these lines. Regional plans and climate change were issues that did not exist for us before" (P9). However, according to the relevant literature, the assessment of the program's results should be carried out during their implementation, towards the end and after the completion of the program, in order to investigate whether the trainees changed their attitude and behavior, while acquiring knowledge and skills (Karalis \& Papageorgiou, 2012; Leftheriotou, 2014).

The implemented programs about climate change were structured as short-term informational meetings and not long-term integrated actions that would help the participants cultivate useful up-to-date skills and change their attitudes towards environmental action. The relevant literature argues that in order for the trainees to adopt a positive stance towards the process of learning, they must be given sufficient time to reflect on their previous experiences and knowledge (Rogers, 2007). It is evident, thus, that the short duration of the programs organized by local bodies is not an ideal condition for the creation of a lasting impact to the participants. Moreover, the fact that the implemented programs did not include a practical part constituted a hindrance in the acquisition of further lived experiences and the development of awareness on the effects of climate change. New trends in adult education support their active involvement for the creation of new experiences, which have proved to be important in the adults' learning process. Admittedly, better learning is achieved by being engaged in action that does not follow a prescribed path (Courau, 1994).

The programs about climate change organized by local bodies in the Prefecture of Larissa aimed at informing, raising awareness, and involving the local community in the process of combating climate change. The study showed that the lack of experienced staff working in the institutions impeded the multifaceted planning of environmental programs in accordance with the existing legal framework and the principles of adult learning. Climate change is a multidimensional problem that necessitates the taking of serious, systematic, and consistent action from the State at a local, national and international level (European Commision, 2008) so as to meet the educational goals that have been set. Brekovic (2012) argues that the cooperation scientific bodies with local authorities is crucial in order to better understand the phenomenon of climate change and to design effective practices that are adapted to the new climatic conditions. The 
present study also revealed that while the investigation of the adult population's characteristics and motivation for participation and learning some of the basic principles of adult education program design (Boone, Safrit \& Jones, 2002), most institutions did not conduct a systematic analysis of the trainees' needs. Instead of placing emphasis on the profile of the participants and problems faced by the local community, the interviewed bodies evaluated their external environment for the organization of the program, which, in this case, was the phenomenon of climate change and their members' experience in the planning of similar educational events (Leftheriotou, 2014).

Moreover, many institutions did not structure the content of their programs according to the sections, educational goals and optimal duration that are suggested by Boone, Safrit \& Jones (2002). Instead of building the content of the program on the participants' identified needs and wants, the institutions determined its structure based on the nature of the speaker's expertise and their particular interests (Leftheriotou, 2014).

With reference to infrastructure employed in the programs, the research indicated that institutions regard it as a typical organizational process that does not require a significant amount of time or proper planning. In any case, the study showed that the infrastructure available to the institutions does not exhibit variety and does not receive adequate funding for the application of new and innovative methods and tools that could motivate participants to change their current stance and adopt eco-friendly habits (UNFCCC, 2012).

Selecting trainers of the educational programs didn't require their expertise on adult training as a prerequisite, but it has been based on their professional experience and their academic qualifications. According to a recent study by CEDEFOP, (PROFF, 2004) the basic criteria for the selection of trainers in an adult education program are their relative education and certification, their previous experience on adult education programs and their work with particular target populations. Moreover, it is also important for them to have thorough knowledge of the content and to be able to effectively evaluate the subject matter of the program in order to adapt it to the trainees' profile. The absence of adult education trainers implies the lack of the knowledge needed to organize experiential activities according to the participants' characteristics. Thus, the programs fail in raising the trainees' interest and in creating the optimal conditions for their learning. However, through participation in programs that are based on adult education principles, the trainees are able to gain the necessary experiences and to develop their critical thinking in order to meaningfully understand the phenomenon of climate change and become active citizens (Anderson, 2010).

The process of educating people on climate change in combination with the development of new programs and appropriate techniques will help meet the goals set by Environmental Education. These goals are mostly concerned with raising people's awareness and with informing them on environmental issues, while also motivating them to adopt a responsible attitude towards confronting these problems (Sauvé, 1996). However, the bodies that were examined for this research did not seem to reflect on whether their programs' initial goals were realized something that could be a result of 
the organizers' little experience in this area and their inability to communicate effectively with the participants. In any case, the principles of adult education specify that the design and evaluation of the program are complementary procedures that are necessary for the improvement of the programs' nature and quality (Caffarella 2002; Nadler \& Nadler 1994; Leftheriotou, 2014).

In order to participate in actions to protect the environment, one must have developed environmental awareness and consciousness (Thakur, 2012). In the present study, environmental awareness seemed to have been partially acquired by some associations and citizens that care about being regularly trained. Some of trainees took the initiative to organize environmental actions such as cleaning paths and beaches, changing their crops to more eco-friendly options, recycling, saving energy, using bikes etc. Therefore, there were few cases pointing to the fact that the participants developed environmental consciousness and became active citizens who claim their rights, protect and respect the environment, while they also take actions guided by a strong sense of responsibility, justice and need to support their community (Ross, 2007).

Last but not least, it is important to consult the experts in order to create and structure a science-based agenda that would help participants realize the consequences of climate change and that would provide them with suitable solutions to become adaptable and resilient in the case of extreme weather conditions. Climate change education that is based on the principles of adult education can only be effective when the trainees' educational needs are placed at the center of attention, when they have a thorough understanding of the subject matter, and when they are engaged in experiential learning (Sterling, 2008). If the aforementioned conditions are met, the participants are able to develop environmental awareness and critical thinking (Sterling, 2008). In any case, the citizens are the ones affecting the policies implemented towards the mitigation of climate change (U.S., 2009). The competent institutions and the state must insist on taking actions about the citizens' information and must adapt the programs to the adult trainees' needs, while they also evaluate the achievement of the event's goals and set new targets according to the national and international climate policies (Anderson, 2010).

\section{Recommendations}

Despite the fact that this study was conducted on a local scale, its findings seem to be not only timely, but also useful. These results could be utilized by the local bodies executives' and members who organize environmental programs that are addressed to citizens and professionals. By exploiting the data yielded by the research, local bodies could properly design programs that are based on the principles of adult education and which serve the local communities' need for information, environmental awareness and action-taking at an individual and collective level. Moreover, the institutions can employ these findings to improve the procedure they follow for the design and implementation of educational programs in order to create events of higher quality. 
For future reference, a comparative study between the climate change-related actions of local bodies and the state policies in different countries would be of great interest, as well as the investigation of the motivation, the needs, the expectations that the trainees have and the obstacles they encounter when participating in such programs. Another topic worthy of research would be to evaluate the strong and weak points of the environmental education programs offered, in order to improve their quality and contribute to the development of sufficient environmental consciousness and actiontaking at an individual and at a collective level.

\section{Conclusion}

Environmental education through programs that follow the principles and specifications of adult education program design can bring social change and succeed in helping citizens adapt to climate change. The absence of environmental education renders people vulnerable to phenomena such as extreme weather events, poverty, illness, and unemployment. The examination of the program's external and internal environment, the analysis of the target population needs, and the evaluation of the program should constitute basic steps in the process of planning and implementing programs and actions about climate change. In the case that the above procedures are not followed, the programs organized would be of low quality, ineffective and unable to fulfill their initial goal or cater for the needs of the participants. Moreover, by appropriately organizing, disposing, and utilizing the necessary material resources, by adding experiential activities to the environmental programs organized and by optimizing the use of human resources according to the principles of adult education, the local institutions could significantly raise the events' effectiveness and meaningfully contribute in the effort to combat climate change.

Effective climate education must be human-centered, since citizens are the ones that influence the policies that are implemented towards the mitigation of climate change (U.S., 2009). The competent institutions must persist on timely and informed actions, must evaluate the extent to which they have achieved their goals and adapt the agenda of the programs to the educational needs of the participants, while promoting qualitative information (Anderson, 2010). The application of the current national plan on climate change and the development of environmental awareness is the only sustainable solution from a social, environmental, and financial aspect. Otherwise, the consequences of this phenomenon at a national, European, and international level would be extremely severe. Environmental education through properly designed educational programs that are based on the principles of adult education can safely lead to the development of individual and collective environmental awareness and ultimately bring social change.

\section{Acknowledgements}

We would like to thank all the people who participated in this study. 


\begin{abstract}
About the Authors
Bechlivani Sofia was born in Larissa in 1982 and graduated from the School of Geology (Faculty of Sciences, Aristotle University of Thessaloniki) in 2005. She, then, worked in the construction industry and in the field of quality control of building materials in the region of Thessaly. At the same time, in the following years, she completed her postgraduate studies on "Mineral Resources and Environment" at the School of Geology (Faculty of Sciences Aristotle University of Thessaloniki) in 2010. She, then, dealt extensively with laboratory testing of quarry materials and issues on compliance with legislative requirements and environmental conditions during the production process. She has, also, dealt with the implementation of quality systems in the manufacturing and production sector as well as the drafting of educational material in quality standards. In recent years, after attending some seminars in adult education, she discerned her interest in this field and thus completed another postgraduate course in "Lifelong Learning and Leadership in Education-Education Sciences" at the School of Early Childhood Education (Faculty of Education Aristotle university of Thessaloniki) in 2021.
\end{abstract}

Maria Pavlis-Korres obtained a university degree in Political Science in Athens. From 1983 until 2018 she worked on Adult Education in the Greek Ministry of Education. Since 2005 her research interests are focused on e-learning and she became a PhD student in the University of Alcalá, Spain. In 2008 she obtained her Advance Studies Degree from the Computer Science Department of the University of Alcalá and in 2010 she obtained her PhD with honors. Since 2012 she is a member of the scientific staff of Hellenic Open University and teaches in "Adult Education" and "Education Science" postgraduate programs. In June 2017 she has been elected Associate Professor in the Pedagogical Sector of the Aristotle University of Thessaloniki to teach "Lifelong Learning and non-Formal Education". She has published several articles, chapters and books on Roma, adult education, and e-learning. Her current interests are focused on design, development, and evaluation of educational projects for adults, face to face and e-learning, as well as the group dynamics in an online environment and the appropriate use of communication tools in order to promote interaction in an online environment.

\title{
References
}

Adger, WN., Agrawala, S., Mirza, M., Conde, C., \& O’Brien, K. (2007). Assessment of adaptation practices, options, constraints, and capacity. See Ref. 114, pp. 717-43.

Anderson, A. (2010). Combating climate change through quality education. Washington, DC: Brookings Global Economy and Development.

Bandounas, A. (2018). Teachers' views, attitudes and perceptions regarding climate change and global warming: a case study: teachers of UE70 primary education in the Prefecture of Dodecanese (Postgraduate Thesis, University of the Aegean) (in Greek). Retrieved from https://hellanicus.lib.aegean.gr/handle/11610/18531 
Bell, J. (2005). Doing your research project: A guide for first time (4th Edition). Researches in science education and Social sciences.

Bernard, H. R., Wutich, A., \& Ryan, G. W. (2016). Analyzing qualitative data: Systematic approaches. Sage publications.

Boone, E. J., Safrit, R. D., \& Jones, J. (2002). Developing programs in adult education: A conceptual programming model. Waveland Press.

Brekovic, A. (2012). Climate change and local government (Postgraduate Thesis, University of the Aegean). Retrieved from https://hellanicus.lib.aegean.gr/bitstream/handle/11610/7167/file1.pdf?sequence= 1 \&isAllowed $=\mathrm{y}$

Brink, J.P., \& Wood, J.M. (1998). Advanced design in nursing research (2nd ed.). London: Sage publications.

Caffarella, Rosemary (1988). Program Development and Evaluation: Resource Book for Trainers. New York: John Wiley and Sons.

Caffarella, R. S. (2002). Planning Programs for Adult Learners: a Practical Guide for Educators, Trainers and Staff Developers. San Francisco: Jossey-Bass.

CEDEFOP. (2004). Competence Grid. Cedefop, Thessaloniki.

Cotter, B., \& Hannan, K. (Environs Australia). (1999). Our Community Our Future: A Guide to Local Agenda 21, Commonwealth of Australia, Canberra, Australia.

Courau S. (1994). Les outils d' excellence du formateur ( $2^{\text {nd }}$ ed.) Paris: ESF.

Elias, J. L. \& Merriam, S. B. 2005. Philosophical Foundations of Adult Education. Florida: Krieger Publishing Company.

European Commission. (2005). Report on demonstrable progress under the Kyoto Protocol (required under Article 5(3) of Decision 280/2004/EC concerning a mechanism for monitoring Community greenhouse gas emissions and for implementing the Kyoto Protocol) Brussels, COM (2005) 615, Brussels.

European Commission. (2007). European Environment Agency (2005b). The European environment- State and outlook 2005, Copenhagen: EEA. Retrieved from https://www.eea.europa.eu/publications/state of environment report 20051

European Commision. (2008). Regional Policy, sustainable development and climate change. Retrieved from https://ec.europa.eu/regional policy/el/information/publications/panoramamagazine/

European Commission. (2009). Climate change. Publications Europa.eu. Retrieved from https:/ec.europa.eu/environment/pubs/pdf/factsheets/climate_change.pdf

European Environmental Agency. (2016). Climate change, impacts and vulnerability in Europe 2016. Retrieved from https://www.eea.europa.eu/publications/climatechange-impacts-and-vulnerability-2016

Gouli, D. (2017). The Environmental Education Centers (EEC) as institutions for the introduction and implementation of innovative actions and programs: The views of the heads of operation of EEC (Postgraduate Thesis, University of Western Macedonia) (in Greek).

Retrieved from 
https://dspace.uowm.gr/xmlui/bitstream/handle/123456789/1820/\%CE\%93\%CE\% 9A\%CE\%9F\%CE\%A5\%CE\%9B\%CE\%97\%20\%CE\%94\%CE\%97\%CE\%9C\%CE\%97 $\% \mathrm{CE} \% \mathrm{~A} 4 \% \mathrm{CE} \% \mathrm{~A} 1 \% \mathrm{CE} \% 91 . p d f ?$ sequence $=1 \&$ is Allowed $=\mathrm{y}$

Guest, G., MacQueen, K. M., \& Namey, E. E. (2011). Applied thematic analysis. Thousand Oaks, CA: Sage.

Hopkins, C., Damlamian, J., \& Ospina, G. (1996). Evolving education for sustainable development: An international perspective. Nature \& Resources, 32(3), 2-11

Intergovernmental Panel on Climate Change - IPCC. (2007). Synthesis report. In Core

Writing Team, R. K. Pachauri, \& A. Reisinger (Eds.), Contribution of Working Groups I, II and III to the Fourth Assessment Report of the Intergovernmental Panel on Climate Change (104 pp.). Geneva: Switzerland: IPCC.

Intergovernmental Panel on Climate Change - IPCC. (2014). Climate change 2014: Synthesis report. In Core Writing Team, R. K. Pachauri, \& L. A. Meyer (Eds.), Contribution of Working Groups I, II and III to the Fifth Assessment Report of the Intergovernmental Panel on Climate Change (151 pp.). Geneva: Switzerland. IPCC. ISBN 978-92-9169-143-2

Jarvis, P. (1985). The Sociology of Adult and Continuing Education. London: Croom Helm. Jarvis, P. (2004). An international dictionary of adult and continuing education. Routledge.

Karalis, Th., \& Papageorgiou, I. (2012). Design, Implementation and Evaluation of Lifelong Learning Programs. Athens: INE-GSEE.

Kartalis, K., Kokkosis, Ch., Oikonomou, D., Santamouris, M., Agathangelidis, I., Polydoros, A., \& Koutsopoulou, A. (2017). The Impact of Climate Change on Development. Dianeosis - Organization for Research and Analysis. Retrieved from https://www.dianeosis.org/wpcontent/uploads/2017/06/climate change10.pdf

Knowles, M. S. (1980). The modern practice of adult education. New York: Cambridge. The Adult Education Company.

Knowles, M. S., Holton III, E. F., \& Swanson, R. A. (1998). The adult learner: The definitive classic in adult education and human resource development. th Houston. TX: Gulf Publishing Company.

Laissy, A. P. (2008). Regional policy, sustainable development and climate change. Retrieved from

https://ketlib.lib.unipi.gr/xmlui/bitstream/handle/ket/535/mag25 en.pdf?sequenc $\underline{\mathrm{e}=2}$

Leftheriotou, P. (2014). Adult Education Programs Design in Greece: the case of General Secretariat for Lifelong Learning. (Doctoral Dissertation, Hellenic Open University) (in Greek). Available from the database of the National Archive of Doctoral Dissertations (Code 30097).

Leftheriotou, P., \& Pavlis Korres, M. (2014). General Adult Education Programs by the General Secretariat of Lifelong Learning: past, present and future. In A. Kyridis (Ed.), Vulnerable Social Groups and Lifelong Learning, (pp. 151-193). Athens: Gutenberg. (In Greek). 
McKeown, R., \& Hopkins, C. (2010). Rethinking climate change education. Green Teacher, (89), 17.

Mitigation, C. C. (2011). IPCC special report on renewable energy sources and climate change mitigation. Renewable Energy, 20(11).

Mochizuki, Y., \& Bryan, A. (2015). Climate change education in the context of education for sustainable development: Rationale and principles. Journal of Education for Sustainable Development, 9(1), 4-26.

Moseley, J. L., \& Heaney, M. J. (1994). Needs assessment across disciplines. Performance Improvement Quarterly, 7(1), 60-79.

Nadler, L. \& Nadler, Z. 1994. Designing Training Programs: The Critical Events Model. Houston: Gulf Publishing.

Pistela, M. (2020). In Service Science Teachers' Knowledge, Beliefs and Attitudes about Climate Change (Postgraduate Thesis, Hellenic Open University) (in Greek). Retrieved from https://apothesis.eap.gr/handle/repo/48324

Polit, F. D., \& Hungler, P. B. (1999). Nursing research: Principles and methods. Philadelphia: Lippincott.

Rogers, A. (2007). Teaching Adults. Open University Press.

Ross, A. (2007). Multiple identities and education for active citizenship. British Journal of Educational Studies, 55(3), 286-303.

Sauvé, L. (1996). Environmental Education and Sustainable Development: A Further Appraisal. Canadian Journal of Environmental Education, 1, 7-34

Sterling, S. (2008). Sustainable education - towards a deep learning response to unsustainability. Policy \& Practice: A Development Education Review. Vol. 6, pp. 6368.

Thakur, K. (2012). A study of Environmental awareness among senior secondary school students of Chandigarh. International Indexed and Referred Research Journal. Vol. 4, pp.16-18.

UNESCO. (1976). Foundations of Lifelong Learning. Oxford: UNESCO Institute for Education,

UNESCO. (2003). United Nations Decade of Education for Sustainable Development (January 2005-December 2014): Framework for a Draft International Implementation Scheme. Paris: UNESCO.

UNESCO. (2005). United Nations Decade of Education for Sustainable Development (20052014): International Implementation Scheme. Paris: UNESCO. Retrieved from http://unesdoc.unesco.org/images/0014/001486/148654E.pdf

UNFCCC. (2012). Momentum for Change in 2012: Momentum for Change-Change for Good. Bonn: UNFCCC Secretariat.

UNFCCC. (2016). Aggregate effect of the intended nationally determined contributions: an update. Synthesis report by the secretariat, UN Doc FCCC/CP/2016/2.

U.S. Global Change Research Program (USGCRP). (2009). Climate literacy: The essential principles of climate sciences - A guide for individuals and communities. Washington, DC: Department of Commerce, National Oceanic and Atmospheric 
Administration.

Retrieved

from

http://www.globalchange.gov/resources/educators/climate-literacy

Creative Commons licensing terms

Author(s) will retain the copyright of their published articles agreeing that a Creative Commons Attribution 4.0 International License (CC BY 4.0) terms will be applied to their work. Under the terms of this license, no permission is required from the author(s) or publisher for members of the community to copy, distribute, transmit or adapt the article content, providing a proper, prominent and unambiguous attribution to the authors in a manner that makes clear that the materials are being reused under permission of a Creative Commons License. Views, opinions and conclusions expressed in this research article are views, opinions and conclusions of the author(s). Open Access Publishing Group and European Journal of Education Studies shall not be responsible or answerable for any loss, damage or liability caused in relation to/arising out of conflicts of interest, copyright violations and inappropriate or inaccurate use of any kind content related or integrated into the research work. All the published works are meeting the Open Access Publishing requirements and can be freely accessed, shared, modified, distributed and used in educational, commercial and non-commercial purposes under a Creative Commons Attribution 4.0 International License (CC BY 4.0). 